\title{
The effects of preexperimental diet upon reward magnitude effects
}

\author{
ROBERT E. PRYTULA \\ Middle Tennessee State University, Murfreesboro, Tennessee 37132 \\ STEPHEN F. DAVIS \\ Austin Peay State University, Clarksville, Tennessee 37040
}

and

JAMES W. VOORHEES

Texas Christian University, Fort Worth, Texas 76129

\begin{abstract}
Three groups of rats were reared from weaning on differing diets in order to assess the influence of this preexperimental manipulation on reward magnitude effects. Subgroups within each diet condition received large and small reward, respectively, during the course of 29 straight-runway trials. Reward magnitude effects developed in start, run, and goal measures. Additionally, significant differences between diet conditions were found in the start measure.
\end{abstract}

Considerable controversy has been generated recently concerning the reliability and validity of reward magnitude effects. At best, the once widely held assumption that large magnitudes result in superior performance appears to be on somewhat shaky ground. Data reported by Black (1969), Campbell, Batsche, and Batsche (1972), McCain (1970), and McCain, Dyleski, and McElvain (1971) have suggested, rather convincingly, that under some conditions reward magnitude effects may be rather transitory, if they develop at all.

Research attempting to delineate the relevant variables in the reward magnitude phenomenon has dealt primarily with factors directly related to the testing situation and/or analysis of the data. For example, Campbell et al. (1972) investigated possible satiation effects, Daly (1972) and McCain (1969) reported singlevs. multiple-pellet effects, and McCain (1970) and McCain et al. (1971) examined the effects of extended training; furthermore, some studies have reported latencies (e.g., McCain, 1970), while others have empolyed transformed scores (e.g., Daly, 1972). Additionally, a divergence in type of measure reported can be found (e.g., Davis, Prytula, \& Seago, 1976; McCain, 1970).

On the other hand, as Davis (1974) and Hulse (1973) point out, preexperimental procedures, such as pellet habituation, may have a pronounced effect on behavior shown during the test situation. The present study sought to investigate the effect of one preexperimental condition, rearing diet, on reward magnitude effects.

This research was supported by a faculty research grant from Middle Tennessee State University to the first author and a Tower Fund research grant from Austin Peay State University to the second author.
More specifically, previous data (Davis et al., 1976) had suggested that one of the factors producing the collapse of the reward magnitude effect was an increase, possibly due to dissipation of inhitition, in the performance of the small-reward subjects. One possible source of this inhibition might well be the contrast that exists between the reward received in the experimental apparatus and the home-cage ration. The larger the contrast and the greater the similarity between these two, the larger the resultant inhibition. By manipulating rearing diet from weaning, it was hoped that the influence of this possible interaction might be shown more directly.

\section{METHOD}

\section{Subjects}

Fifty-four male albino rats purchased from the SpragueDawley Company, Madison, Wisconsin, served as subjects. All subjects were 22 days of age upon arrival at the laboratory, and were individually caged for the duration of the experiment.

\section{Apparatus}

A single straight runway $(11.43 \times 12.70 \mathrm{~cm})$ having a $38.10-\mathrm{cm}$ gray startbox, a $91.44-\mathrm{cm}$ black run section, and a $30.48-\mathrm{cm}$ black goalbox, seerved as the experimental apparatus. A microswitch mounted on the start door, in conjunction with a series of photoelectric cells and Standard Electric timers, yielded start, run, and goal latencies for each trial. A plastic goal cup was recessed into the end wall of the goalbox. Hardwarecloth tops covered the entire apparatus.

\section{Procedure}

Rearing diets. Upon receipt from the supplier, the rats were randomly assigned to one of three diet conditions: (1) Purina Laboratory Chow-B, (2) Noyes pellets-P, and (3) liquid-L. Subjects in Groups B and $P$ were reared on free-feeding diets consisting of Purina Laboratory Chow bricks and 45-mg Noyes pellets, respectively. Subjects in Group $\mathrm{L}$ were reared on a free- 
feeding diet consisting of three parts water, one part pulverized Purina Laboratory Chow, and one teaspoon Sugar Twin for each $250 \mathrm{~g}$ of mixture. Wide-mouth jars affixed to the front of each cage were used as food containers for Groups $P$ and $L$. These diets remained in effect during rearing and experimental testing. Water was freely available at all times in the home cage. Weight comparisons of the subjects in the various diet conditions were made at the beginning and end of the 58-day rearing period to insure that growth rates were similar. No significant differences were found.

Testing procedure. All subjects were reared on their respective diets for 58 days (i.e., until the subjects were 80 days old). At this time, Groups $B, L$, and $P$ were each randomly divided into two subgroups: small reward (B-1, L-1, P-1) and large reward (B-12, L-12, P-12). Small-reward subjects received 145 -mg Noyes pellet on subsequent runway trials, while largereward subjects received $1245-\mathrm{mg}$ Noyes pellets on all subsequent runway trials.

A food-deprivation regimen which maintained all subjects at $85 \%$ of their free-feeding body weight was begun 7 days prior to runway training and remained in effect for the duration of the experiment. On each of the 2 days immediately preceding the start of runway training, each subject received a 5-min exploration period in the unbaited runway. All photoelectirc equipment was operative on these days. No additional pretraining procedures were employed.

Runway training lasted 10 days. Two trials were administered on the first day, with three trials being administered on all subsequent days. Thus, each subject received a total of 29 trials. The sequence for running subjects was randomly determined each day.

\section{RESULTS AND DISCUSSION}

All latencies were reciprocated and when multiplied by the appropriate constant yielded speed scores in meters per second. Mean start, run, and goal speeds for the 10 days of runway training are shown in Figures 1-3, respectively. Analysis of variance was performed on the data from the last 4 days of training (the point at which maximum differences appeared to have developed), and showed that the reward magnitude effect was significant in all measures [start: $F(1,48)=8.18, p<.01$;

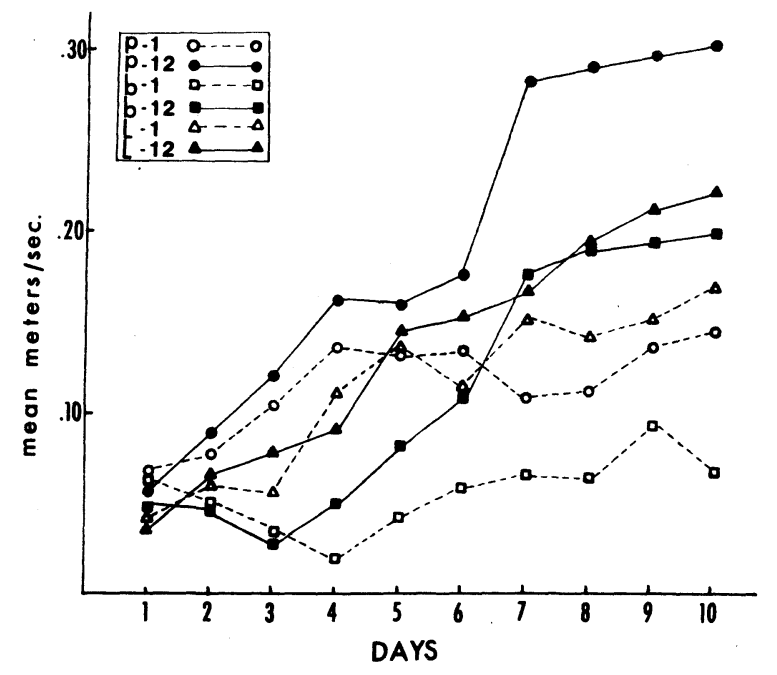

Figure 1. Mean start speeds (meters per second).

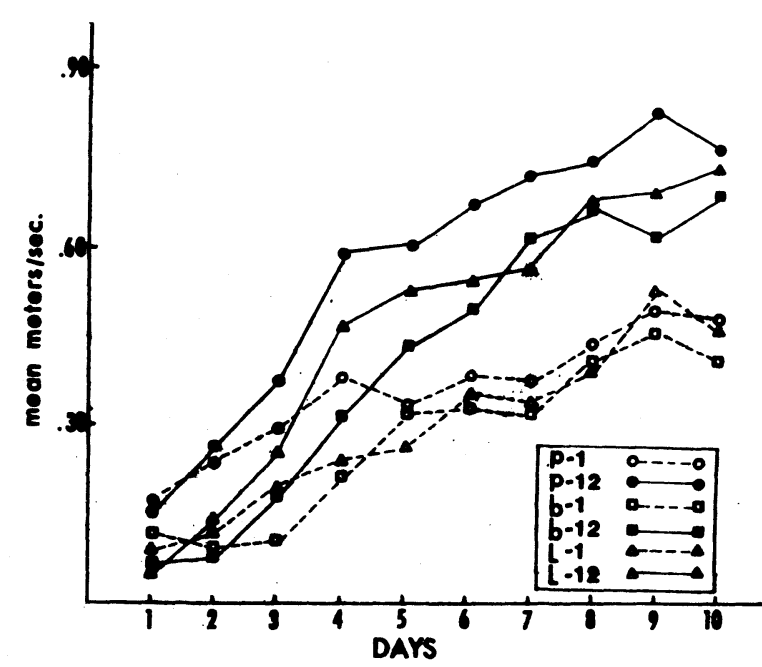

Figure 2. Mean run speeds (meters per second).

run: $F(1,48)=7.37, p<.01 ;$ goal: $F(1,48)=5.07$, $\mathrm{p}<.05]$. Additionally, the diet factor was found to be significant $[\mathrm{F}(2,48)=5.20, \mathrm{p}<.05]$ in the start measure. Subsequent Newman-Keuls procedure showed that the pellet-reared (P) subjects were starting faster $(p<.05)$ than all other subjects, and that the liquidreared $(L)$ subjects were starting faster $(p<.05)$ than the brick-reared (B) subjects.

As there was an interest in the amount of inhibition involved in the performance of the respective groups, it appeared appropriate to consider the differences between the large- and small-reward groups' speeds within each diet condition. To accomplish this, the following analysis was performed for each measure. Mean subject speeds for the last 4 days of training were rank ordered within each subgroup. Subjects occupying the same rank within the subgroups for a particular diet condition were considered as a matched pair (i.e., Rank 1 for Group L-1 was matched with Rank 1 in Group L-12, and so forth). A daily difference score was found by subtracting the speed of the small-reward member of the pair from that of the large-reward member of the pair. These difference scores were then subjected to analysis of variance. A significant diet effect was found only in the start measure $[F(2,24)=16.66, p<.01]$. Subsequent NewmanKeuls analysis showed that Group $P$ had significantly larger $(\mathrm{p}<.01)$ difference scores than did Groups B and L. Further, the difference scores for Group B were significantly larger $(p<.01)$ than those for Group L.

Several points pertaining to this data appear worthy of mention. First, significant magnitude effects developed in all three measures. However, as only 29 trials were administered, one can only speculate as to the permanence of these effects. Despite the graphical suggestion of facilitation of Group P-12 speeds, no significant diet effects were observed in the run and goal measures (Figures 2 and 3, respectively). A consideration of the start-measure results (Figure 1) pre- 


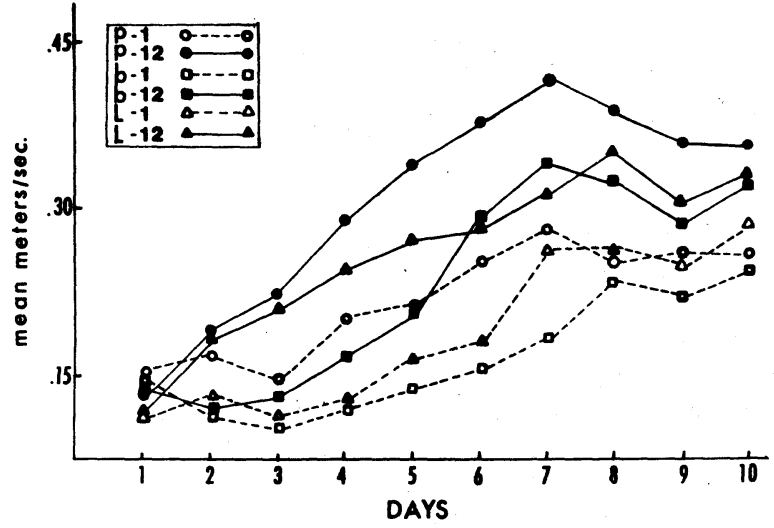

Figure 3. Mean goal speeds (meters per second).

sented a different picture. Here, in addition to reward magnitude effects, significant diet effects were observed.

Turning to the question of possible inhibitory effects influencing the reward magnitude phenomenon, the start-measure results are also informative. As previously mentioned, it might be anticipated that contrast inhibition for Group P-1 would be greater due to similarity of rearing diet and reward received in the test situation. Accordingly, less inhibition, due to decreased similarity, would be expected in the case of Group B-1, and even less in the case of Group L-1. The analysis of the startmeasure difference scores is certainly supportive of this contention. However, due to the dramatic rate of increase in start-measure performance shown by Group P-12 toward the end of training, the importance of these results may seem to pale a bit. It is important to note that, supportive of the inhibition notion, the difference scores of Group B were significantly larger than those of Group L.

Lastly, the confinement of the results supportive of dietary influence to the start measure is consistent with data from the differential-conditioning literature (e.g., Davis, Gilbert, \& Seaver, 1971; Ludvigson \& Gay, $1966,1967)$. This data has shown that the maximal occurrence of inhibition typically coincides with the initial presentation of cues in the startbox.

\section{REFERENCES}

BLACK, R. W. Incentive motivation and the parameters of reward in instrumental conditioning. In W. J. Arnold \& D. Levine (Eds.), Nebraska symposium on motivation. Lincoln: University of Nebraska Press, 1969.

Campbell, P. E., Batsche, C. J., \& Batsche, G. M. Spaced-trials reward magnitude effects in the rat: Single versus multiple food pellets. Journal of Comparative and Physiological Psychology, 1972, 18, 360-364.

DALY, H. B. Learning to escape cues paired with reward reductions following single- or multiple-pellet rewards. Psychonomic Science, 1972, 26, 49-52.

DAvis, S. F. Runway performance as a function of pellet habituation. Perceptual and Motor Skills, 1974, 39, 252.

Davis, S. F., Gilbert, R. F., \& Seaver, W. E. III. Stimulus onset and its effect on $\mathrm{S}+$ and $\mathrm{S}$ - performance in differential conditioning. Psychonomic Science, 1971, 25, 29-31.

Davis, S. F., Prytula, R. E., \& Seago, J. D. Hey Garvin! Science is a game: A reply to McCain, Ward, \& Lobb. Bulletin of the Psychonomic Society, 1976, 7, 93-95.

Hulse, S. H. Patterned reinforcement. In G. H. Bower (Ed.), The psychology of learning and motivation: Advances in research and theory (Vol. 7). New York: Academic Press, 1973. Pp. 313-362.

Ludvigson, H. W., \& GAY, S. E. Differential reward conditioning: $\mathrm{S}$ - contrast as a function of the magnitude of $\mathrm{S}+$. Psychonomic Science, 1966, 5, 289-290.

Ludvigson, H. W., \& GAY, R. A. An investigation of conditions determining contrast effects in differential reward conditioning. Journal of Experimental Psychology, 1967, 75. 37-42.

McCain, G. Different levels of performance with equivalent weights of reward. Psychonomic Science, 1969, 14, 2-3.

McCaIn, G. Reward magnitude and instrumental responses: Consistent and partial reward. Psychonomic Science, 1970, 19, 139-141.

McCain, G., Dyleski, K., \& McElvain, G. Reward magnitude and instrumental responses: Consistent reward. Psychonomic Monograph Supplements, 1971, 3, 16(Whole No. 48$)$.

(Received for publication November 15, 1977.) 